\title{
Choline in Pediatric Depression
}

\author{
Frank P MacMaster*, Vivek Kusumakar
}

\begin{abstract}
Purpose of Study: The prefrontal cortex has been previously implicated in the neuropathology of major depressive disorder (MDD). Hence, we used proton magnetic resonance spectroscopy (1H-MRS) to examine choline levels in the prefrontal cortex of youth with major depression. Basic Procedures: Twelve age- and sex-matched case-control pairs were examined (age range 10 to 18 years, 7 females and 5 males in each group). All subjects were treatment naive at the time of the scan. A long echo $1 \mathrm{H}-\mathrm{MRS}$ scan was acquired from the right prefrontal cortex (4cc) in all subjects. Main Findings: Right prefrontal Choline/Creatine ratios were elevated in the youth with mood disorders $(F 1,11=10.741, p=0.007)$ as compared with healthy controls. Principal Conclusions: These findings suggest that prefrontal cytosolic choline may be increased in youth with MDD in comparison with healthy controls. This is consistent with reported findings in both adults and adolescents and suggests that MDD in youth is associated with alterations in choline metabolism in the prefrontal cortex.
\end{abstract}

KEY WORDS: choline, depression, magnetic resonance spectroscopy, pediatric, prefrontal cortex.

\section{INTRODUCTION}

Numerous proton magnetic resonance spectroscopy (1H-MRS) studies have linked cytosolic choline levels to the neuropathology of mood disorders (1-7). Increases in choline in depressed subjects have been noted in adults $(1,3)$ and in pediatric samples $(4,5)$. Conversely, two studies demonstrated reduction in choline $(6,7)$. Auer and others (8) did not note any significant difference in choline levels in the cingulate in their study of MDD subjects and controls. The choline resonance derived by $1 \mathrm{H}-\mathrm{MRS}$ arises mainly from phosphocholine and glycerophosphocholine $(9,10)$.

Children and adolescents have been relatively understudied with regard to the neurobiology of mood disorders. This is despite the fact that the prevalence of

\footnotetext{
* To whom correspondence should be addressed: Frank P MacMaster, 5909 Veterans Memorial Lane, 9th Floor - Psychiatry, Abbie J Lane Memorial Building, QE II Health Sciences Centre, Halifax, Nova Scotia, Canada, B3H 2E2

Phone: 902-473-4571, Fax: 902-473-4596

email: fpmacmas@dal.ca
}

depression increases during adolescence, rising from $1 \%$ up to adult levels (6-8\%). Mood disorders in youth are associated with impairment in social, family and academic functioning, are highly predictive of future episodes and are significantly related to suicide (11). Despite the prevalence and outcomes associated with the mood disorders, there is a paucity of information about the etiology. Hence, studies of children and adolescents are necessary in order to determine if abnormalities noted in adult populations occur across the life span, how early they present during development, and whether they can be used as predictors for future risk of developing depression. Studies early in the course of an illness also avoid the potential confounds of illness chronicity, hospitalization and long-term medication use. This study endeavors to uncover neurobiological correlates of juvenile depression. Based on the adult literature (1$3,6,7)$ and the reports on pediatric depression $(4,5)$, we hypothesized that youth with MDD and those without psychiatric illness will demonstrate differences with regard to cytosolic choline in the prefrontal cortex. 


\section{METHODS}

\section{Subjects}

Subjects were recruited through either of two methods: (1) advertisements, or (2) as participants in clinical treatment (combined pharmacological and psychotherapy) programs. All subjects and one of their parents/guardians signed informed consents for the study after a full explanation of the procedures in accordance with the Research Ethics Board approval provided by the IWK Health Centre. Each subject completed the Children's Depression Rating Scale $(\mathrm{CDRS})(\operatorname{mood}$ disorder group mean $=66.083+$ 14.042) at the time of scan. Diagnosis based on KiddieSchedule for Affective Disorders and SchizophreniaPresent and Lifetime Version (K-SADS-PL) criteria were established by a board-certified psychiatrist (primarily VK). Twelve subjects (5 males, 7 females) aged 10 to 18 years old with MDD and twelve age and sex-matched healthy controls participated in this study. All subjects were treatment naive at the time of the scan. All data is reported as mean $+/$ - standard deviation unless otherwise specified. Exclusion criteria for participation in this study included a history of neurological illness, serious medical illness, claustrophobia, age greater than 18 years, or the presence of a ferrous implant or pacemaker.

\section{Magnetic Resonance Spectroscopy Procedures}

Scans were conducted at the Queen Elizabeth II Health Sciences Centre using a Siemens Magnetom Vision 1.5 Tesla scanner. Multi-slice scout images (axial, coronal and sagittal planes) were used for voxel orientation. Special care was taken to ensure adequate coverage of the right prefrontal gray matter by the voxel. A long echo proton magnetic resonance spectroscopic imaging (1H-MRS) procedure was used to acquire spectra from the sample. Parameters were as follows: $\mathrm{TE}=135 \mathrm{~ms}, \mathrm{TR}=1500 \mathrm{~ms}$, acquisitions 256 , voxel $=4 \mathrm{cc}$, time $=8$ minutes (see Figure 1 for sample spectra). A trained MRS analyst (FPM) analyzed data in a blind manner. MRS metabolites that can be visualized with this technique are $\mathrm{N}$-acetyl-aspartate (NAA, $2.02 \mathrm{ppm})$, creatine/phosphocreatine (Cr, 3.03ppm) and choline compounds (Cho, 3.20ppm). Following a convention that minimizes variations in the magnetic field homogeneity, metabolite concentrations are expressed as ratios of peak areas (i.e. NAA/Cr, $\mathrm{Cho} / \mathrm{Cr}$ ).

\section{Statistical Analysis}

A repeated measures ANOVA was used to determine group differences in choline levels between MDD patients and healthy age and sex-matched controls. We expected that close age and sex- matching allows for a reduction in the potential confounds of sex and age on

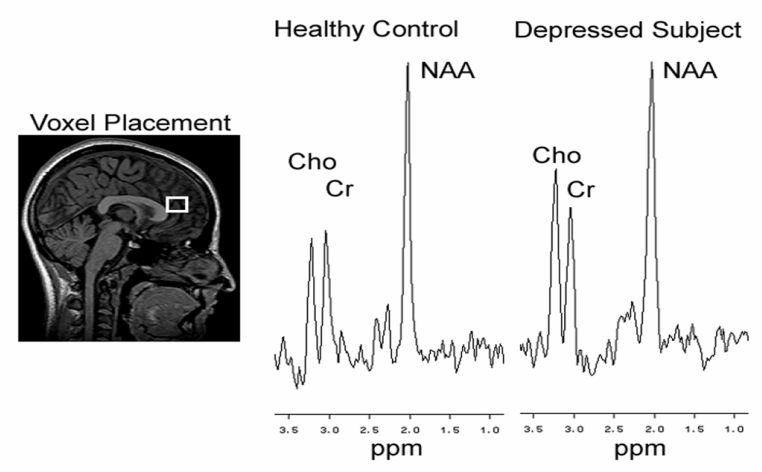

Figure 1. Voxel placement and spectra from a healthy control and a depressed adolescent. NAA $=$ N-Acetyl-Aspartate, $\mathrm{Cr}=$ Creatine/Phosphocreatine, Cho $=$ Choline compounds .

the data set. Correlations (two-tailed) between metabolites and age and, in the psychiatric group, depressive symptom severity were also conducted.

\section{RESULTS}

The two groups did not differ with regard to age (control group mean $=14.917$ years +2.575 , mood disorder group mean $=14.750$ years +2.454 , $\mathrm{t} 11=$ $1.000, \mathrm{p}=0.339)$. Cho/Cr ratios were increased $(39 \%)$ in right prefrontal cortex in the MDD group as compared to matched healthy controls (control mean $=$ $0.782+0.170$, MDD group mean $=1.088+0.368, \mathrm{~F} 1$, $11=10.741, \mathrm{p}=0.007)$. Right prefrontal NAA/Cr did not differ between the healthy controls and MDD subjects (control mean $=2.135+0.378$, MDD group mean $=2.408+0.490, F 1,11=2.702, p=0.129)$. In the control group, $\mathrm{Cho} / \mathrm{Cr}$ demonstrated a trend for inverse correlation with age in years $(\mathrm{r}=-0.516, \mathrm{p}=0.087)$ but not in the MDD group $(r=0.343, p=0.284)$. In the MDD group, Cho/Cr demonstrated a weak trend for positive correlation with CDRS symptom severity score $(\mathrm{r}=0.480, \mathrm{p}=0.117)$

\section{DISCUSSION}

We report a significant increase in $\mathrm{Cho} / \mathrm{Cr}$ in youth with MDD as compared to age- and sex-matched healthy controls in a voxel located in the right prefrontal cortex. This finding is consistent with previous reports of abnormalities in the choline resonance in mood disorders (1-7). Choline acts as a precursor of the neurotransmitter acetylcholine and the membrane lipids, phosphatidylcholine and sphingomyelin. As these lipids are typically bound in the membrane, they contribute little to the MRS choline resonance, while the cytosolic choline compounds, such as glycerophosphocholine (GPC) and phosphocholine (PC) contribute as much as $50 \%$ to the choline signal. Free choline, acetylcholine, and cytidine diphosphate choline make smaller contributions to the resonance 
(12-14). Based on this information, changes in the choline resonance are thought to reflect changes in GPC and/or PC.

It has been postulated that changes in the choline resonance may be reflective of changes in local neuronal metabolism. These changes in metabolism may be required for the incorporation of cytosolic choline compounds into phospholipids. A previous study has shown changes in PET measures of metabolism to be inversely correlated with the $1 \mathrm{H}-\mathrm{MRS}$ choline resonance (15). Steingard and others (4) have also found increases in prefrontal choline in adolescent depression. This is an interesting finding given that the prefrontal cortex has been repeatedly implicated in metabolic neuroimaging studies in mood disorders $(16,17)$.

It is also a possibility that the choline increase demonstrated in the prefrontal cortex of MDD subjects as compared to the controls in this study may reflect differences in glucocorticoid activity. One of the mostreplicated findings in biological psychiatry has been the alteration in the endocrine system in mood disorders. Many mood disorder patients demonstrate hypothalamic-pituitary-adrenal (HPA) axis over activation (18). In conditions that result in excess glucocorticoids, such as Graves disease, Bhatara and others (19) have observed a $32 \%$ reduction in choline. In animal models, orally administered cortisol also reduces $\mathrm{Cho} / \mathrm{Cr}$ levels (20). Glucocorticoids likely adversely affect phosphatidylcholine (Ptd-Cho) metabolism in the brain by inhibiting the activity of enzymes such as phospholipase A2 and C (21). Ptd-Cho plays a role in the second messenger system and signal transduction, as it is a source for diaglycerol (22-25). As an increase in choline has been shown in this report, a primary role for glucocorticoids in this instance may be unlikely.

In emotional processing, the amygdala is required to apply emotional "tone" to a stimulus while the prefrontal cortex provides inhibitory modulation (26). Prefrontal cortex modulation of amygdala function may be diminished in mood disorders, and hence a lack of control over negative cognition may result. Should critical prefrontal inputs to the amygdala be rendered impotent, the inhibitory control of the prefrontal cortex would be lost. Most likely, however, is that the emotional homeostatic mechanisms of both the prefrontal and limbic regions are dysfunctional in mood disorders (27).

Previous work has demonstrated that the prefrontal choline resonance decreases with increasing age in healthy children and adults (28). In our study, only the $\mathrm{Cho} / \mathrm{Cr}$ levels in controls were inversely correlated with age in years. This was not the case for our MDD subjects. As changes in the choline resonance during childhood and adolescence are typically thought to reflect changes in brain development, the lack of a correlation in the mood disorder sample may be indicative of a differential developmental trajectory for these subjects. Alternatively, the change in choline may be wrought by changes in metabolism, signal transduction, or glucocorticoids. These secondary factors may be obscuring the typical developmental trend in choline resonance.

The principle limitations of this study are the small sample size and the heterogeneity of clinical presentation of the MDD group. A further limitation of this study is the lack of absolute quantification of the prefrontal metabolites. However, absolute quantifications are themselves subject to magnetic inhomogeneities and partial volume effects within the region of interest. The use of ratios minimizes the error introduced by variable tissue composition and instrumental instability while allowing the evaluation of relative alterations in metabolites. Further experiments are required to elucidate the exact mechanism of the increase in the $\mathrm{Cho} / \mathrm{Cr}$ peaks and its relation to depressive symptomotology.

We report a significant increase in $\mathrm{Cho} / \mathrm{Cr}$ in youth with MDD as compared to age- and sex-matched healthy controls in a voxel located in the right prefrontal cortex. This fits with previous studies of cytosolic choline in mood disorders. This increase in the $\mathrm{Cho} / \mathrm{Cr}$ ratio may be the result of reductions in metabolism in the prefrontal cortex.

\section{ACKNOWLEGEMENTS}

The Theodore and Vada Stanley Foundation and the Nova Scotia Health Research Foundation supported this project.

\section{REFERENCES}

\section{REFERENCES}

1. Charles HC, Lazeyras F, Krishnan KR, Boyko OB, Payne M, Moore D: Brain choline in depression: in vivo detection of potential pharmacodynamic effects of antidepressant therapy using hydrogen localized spectroscopy. Prog Neuropsychopharmacol Biol Psychiatry 1994; 18:1121-7

2. Hamakawa H, Kato T, Murashita J, Kato N: Quantitative proton magnetic resonance spectroscopy of the basal ganglia in patients with affective disorders. Eur Arch Psychiatry Clin Neurosci 1998; 248: 53-8.

3. Moore CM, Breeze JL, Gruber SA, Babb SM, Frederick BB, Villafuerte RA, Stoll AL, Hennen J, Yurgelun-Todd DA, Cohen BM, Renshaw PF: Choline, myo-inositol and mood in bipolar disorder: a proton magnetic resonance spectroscopic imaging study of the anterior cingulate cortex. Bipolar Disord 2000; 2:207-16.

4. Steingard RJ, Yurgelun-Todd DA, Hennen J, Moore JC, Moore CM, Vakili K, Young AD, Katic A, Beardslee WR, Renshaw PF: Increased orbitofrontal cortex levels of choline in depressed 
adolescents as detected by in vivo proton magnetic resonance spectroscopy. Biol Psychiatry 2000; 48: 1053-61.

5. Rosenberg DR, Paulson LD Seraji-Bozorgzad N, Wilds IB, Stewart CM, Moore, GJ Brain: Chemistry in pediatric depression. Biol Psychiatry 2000; 47:95S.

6. Renshaw PF, Lafer B, Babb SM, Fava M, Stoll AL, Christensen JD, Moore CM, Yurgelun-Todd DA, Bonello CM, Pillay SS, Rothschild AJ, Nierenberg AA, Rosenbaum JF, Cohen BM: Basal ganglia choline levels in depression and response to fluoxetine treatment: an in vivo proton magnetic resonance spectroscopy study. Biol Psychiatry 1997; 41: 837-43.

7. Ende G, Braus DF, Walter S, Weber-Fahr W, Henn FA: The hippocampus in patients treated with electroconvulsive therapy: a proton magnetic resonance spectroscopic imaging study. Arch Gen Psychiatry 2000; 57:937-43.

8. Auer DP, Kraft E, Lipinski B, Schill J, Holsboer F: Reduced glutamate in the anterior cingulate cortex in depression: an in vivo proton magnetic resonance spectroscopy study. Biol Psychiatry 2000; 47: 305-13.

9. Barker PB, Breiter SN, Soher BJ, Chatham JC, Forder JR, Samphilipo MA, Magee CA, Anderson JH: Quantitative proton spectroscopy of canine brain: in vivo and in vitro correlations. Magn Reson Med 1994; 32:157-63.

10. Miller BL, Chang L, Booth R, Ernst T, Cornford M, Nikas D, McBride D, Jenden A: In vivo 1H MRS choline: correlation with in vitro chemistry/histology. Life Sci 1996; 58:1929-35.

11. Birmaher B, Ryan ND, Williamson DE, Brent DA, Kaufman J, Dahl RE, Perel J, Nelson B: Childhood and adolescent depression: a review of the past 10 years. Part I. J Am Acad Child Adolesc Psychiatry 1996; 35(11): 1427-39.

12. Klein J, Gonzalez R, Koppen A, Loffelholz K: Free choline and choline metabolites in rat brain and body fluids: sensitive determination and implications for choline supply to the brain. Neurochem Int 1993; 22:293-300.

13. Frahm J, Bruhn H, Gyngell ML, Merboldt KD, Hanicke W, Sauter R: Localized proton NMR spectroscopy in different regions of the human brain in vivo: relaxation times and concentrations of cerebral metabolites. Magn Reson Med 1989; 11: 47-63.

14. Michaelis T, Merboldt KD, Bruhn H, Hanicke W, Frahm J: Absolute concentrations of metabolites in the adult human brain in vivo: quantification of localized proton MR spectra.
Radiology 1993; 187: 219-27.

15. Duc CO, Weber AH, Trabesinger AH, Meier D, Boesiger P: Recycling the cholines. Int Soc Magn Reson Med 1997; 6:1210.

16. Kennedy SH, Javanmard M, Vaccarino FJ: A review of functional neuroimaging in mood disorders: positron emission tomography and depression. Can J Psychiatry 1997; 42: 467-75.

17. Soares JC, Mann JJ: The functional neuroanatomy of mood disorders. J Psychiatr Res 1997; 31:393-492.

18. Nemeroff CB: The neurobiology of depression. Sci Am 1998; 278: 42-9.

19. Bhatara VS, Tripathi RP, Sankar R, Gupta A, Khushu S: Frontal lobe proton magnetic-resonance spectroscopy in Graves' disease: a pilot study. Psychoneuroendocrinology 1998; 23: 60512.

20. Michaelis T., Ohl F., Fuchs E., Frahm J: Brain metabolite alterations after oral cortisol: a proton MRS study of tree shrews. In Int Soc Magn Reson Med Seventh Scientific Meeting and Exhibition, Philadelphia PA; 1999

21. Khiat A, Bard C, Lacroix A, Boulanger Y: Recovery of the brain choline level in treated Cushing's patients as monitored by proton magnetic resonance spectroscopy. Brain Res 2000; 862:301-7.

22. Exton JH: Hormonal regulation of phosphatidylcholine breakdown. Adv Second Messenger Phosphoprotein Res 1990; 24:152-7.

23. Exton JH: Phosphatidylcholine breakdown and signal transduction. Biochem Biophys Acta 1994; 1212: 26-42.

24. Loffelholz K: Receptor regulation of choline phospholipid hydrolysis. A novel source of diacylglycerol and phosphatidic acid. Biochem Pharmacol 1989; 38: 1543-49.

25. Zeisel SH: Choline phospholipids: signal transduction and carcinogenesis. FASEB J 1993; 7: 551-7.

26. MacMaster FP: Khan SC, Gates L, Kutcher SP, Kusumakar V. Prefrontal modulation of limbic activation during an emotional functional magnetic resonance imaging task. Brain and Cognition 2001; 47: 100-103.

27. Kusumakar V, MacMaster FP, Schmidt M, Khan SC: Frontallimbic morphology in early onset depression. Biol Psychiatry Suppl 2001; 49: 96S.

28. Hashimoto T, Tayama M, Miyazaki M, Fujii E, Harada M, Miyoshi H, Tanouchi M, Kuroda Y: Developmental brain changes investigated with proton magnetic resonance spectroscopy. Dev Med Child Neurol 1995; 37: 398-405.

Frank P. MacMaster is a doctoral candidate in anatomy at Dalhousie University. His thesis is focused on potential diagnostic biomarkers in pediatric psychiatric illness. Mr. MacMaster has a B.A. in psychology and an M.Sc. in Anatomy \& Neurobiology (Neuroscience). Mr. MacMaster uses brain-imaging technologies to study the pediatric brain in vivo. 